\title{
OS NEXOS ENTRE CONCEPÇÃO DO PROCESSO SAÚDE/DOENÇA MENTAL E AS TECNOLOGIAS DE CUIDADOS ${ }^{1}$
}

\author{
Ana Luisa Aranha e Silva² \\ Rosa Maria Godoy Serpa da Fonseca ${ }^{3}$
}

Aranha e Silva AL, Fonseca RMGS. Os nexos entre concepção do processo saúde/doença mental e as tecnologias de cuidados. Rev Latino-am Enfermagem 2003 novembro-dezembro; 11(6):800-6.

A história da humanidade vem inscrevendo convenções sobre doença e tratamento, numa dialética mediada pelas condições materiais e objetivas onde práticas em saúde podem ser identificadas. No campo da saúde mental, podem ser identificados conceitos de adoecimento psíquico e as terapêuticas operadas nos diferentes períodos de desenvolvimento político e econômico e da organização da sociedade humana, dos primórdios à idade contemporânea. Este artigo propõe uma aproximação dos nexos entre a compreensão do processo saúde-doença mental e as formas de tratar, referidos aos dados contextos históricos onde se inscreveram ou se inscrevem, além de buscar o sentido das práticas e sua significação social atual.

DESCRITORES: enfermagem psiquiátrica; história; tendências

\section{CONNECTIONS BETWEEN HEALTH/MENTAL ILLNESS PROCESS COMPREHENSION AND CARE TECHNOLOGIES}

The history of humanity has registered conventions about illness and treatment, in a dialectics that is mediated by material and objective conditions, where health practices can be identified. In the field of mental health, conceptions of psychic sickening and therapeutics can be identified in different periods of political and economic development and in the organization of human society, since the origin of times to the contemporary period. This article proposes a connection between health/mental illness process comprehension and treatments, referring to the historical contexts in which they were/are registered and searches for the meaning of practices and their current social meaning.

DESCRIPTORS: psychiatric nursing; history; trends

\section{LOS NEXOS ENTRE LA CONCEPCIÓN DEL PROCESO SALUD/ENFERMEDAD MENTAL Y LAS TECNOLOGÍAS DE CUIDADO}

La historia de la humanidad inscribiendo convenciones sobre enfermedad y tratamiento, en una dialéctica mediada por las condiciones materiales y objetivas donde prácticas en salud pueden identificarse. En el campo de la salud mental pueden ser identificados conceptos de padecimientos psíquicos y terapéuticos, operados en los diferentes períodos de desarrollo político y económico en la organización de la sociedad humana, desde los primeros tiempos hasta la época contemporánea. Este artículo propone una aproximación de los nexos entre la comprensión del proceso salud-enfermedad mental y las formas de tratarlo, referidos a los contextos históricos dados donde se inscribieron o se inscriben, y buscar el sentido de las prácticas y su actual significado social.

DESCRIPTORES: enfermería siquiátrica; historia; tendencias

\footnotetext{
${ }^{1}$ Fragmento do Projeto de Pesquisa intitulado Por uma tecnologia de enfermagem em saúde mental, apresentado e aprovado em Exame de Qualificação como requisito para obtenção de título de doutor em Enfermagem pelo Programa de Pós-Graduação em Enfermagem da Escola de Enfermagem da Universidade de São Paulo; ${ }^{2}$ Professor Assistente, e-mail: anaranha@usp.br; ${ }^{3}$ Professor Titular, e-mail: rmgsfon@usp.br. Escola de Enfermagem da Universidade de São Paulo
} 
INTRODUÇÃO

Este artigo é parte do Projeto de Pesquisa que busca o aprofundamento do estudo iniciado na Dissertação de Mestrado que analisou um programa de reabilitação psicossocial desenvolvido no Centro de Atenção Psicossocial Prof. Luis da Rocha Cerqueira, da Secretaria de Estado de Saúde de São Paulo, uma instituição de modelo comunitário de assistência à saúde mental, pautado nos pressupostos da Reforma Psiquiátrica brasileira.

O estudo enfocou o trabalho (tomado como instrumento de intervenção da clínica ampliada) realizado por usuários-trabalhadores do serviço e indicou que o projeto terapêutico construído coletivamente, por técnicos e população assistida, interfere de forma positiva e potencializadora na qualidade da assistência prestada e na capacidade de gestão da própria vida, por parte do usuário $^{(1)}$. O impacto desse modo de tratar/cuidar ampliado é conseqüência da articulação do saber operante aliado ao saber prático ${ }^{(2)}$ e ao saber leigo, possibilitadores de reconhecimento, incorporação, apropriação e administração do processo saúde-doença mental, por usuários e trabalhadores. Um desafio que se coloca é o entendimento do campo onde essas aquisições operam, ou seja, a instituição onde a prática se concretiza. $\mathrm{Na}$ dimensão operacional, encontram-se as políticas de saúde norteadoras do projeto terapêutico institucional e a organização do trabalho das diversas práticas sociais que formam a trama ou a rede de sustentação das ações em saúde.

Outra dimensão denominada coletivo institucional refere-se ao condensado das ações em saúde, à essência do projeto terapêutico onde se inscrevem a concepção de ser humano que subjaz à prática e às tecnologias que foram ou são desenvolvidas para alcançar os objetivos de cuidar, ampliar o entendimento e a apropriação do processo saúde-doença pelo portador de transtornos mentais e a melhoria de sua qualidade de vida.

Em síntese, trata-se da necessidade de investigar e analisar o saber que determina as intervenções dos profissionais; o fazer das práticas sociais em saúde, seus nexos e contradições; o saber-fazer e o poder-fazer num modelo assistencial em saúde mental, ou seja, o quadro de referência teórico, os processos de trabalho de técnicos e não técnicos e as tecnologias* de cuidados disponíveis. No campo específico da enfermagem, testemunha-se uma necessidade premente e fartamente observada de atualização conceitual e dos instrumentos de intervenção na experiência de assistência e de ensino.

Este artigo não pretende dar conta de missão tão complexa, tarefa para a tese de doutoramento, mas empreender a busca dos nexos entre a compreensão do processo saúde-doença mental e as formas de tratar, referidos aos dados contextos históricos onde se inscreveram ou se inscrevem e, por meio dessa compreensão, buscar desvelar o sentido das práticas e sua significação social atual.

\section{OS NEXOS ENTRE AS CONCEPCÕ̃ES DO PROCESSO SAÚDE / DOENÇA MENTAL E AS TECNOLOGIAS DE CUIDADOS}

O século $X X$ despede-se legando à humanidade uma velocidade jamais vista, em termos de produção, reprodução e coletivização de saberes. O acúmulo sem precedentes de conhecimentos, forjado pelo saber científico, vem possibilitando a ampliação da expectativa de vida e a melhoria das condições gerais de existência dos seres humanos, ainda que de forma desigual e iníqua.

Um pressuposto da saúde mental, desde a fundação da Psiquiatria pineliana, no nascimento da Medicina Científica do século XIX, é de que a tecnologia de ponta nessa área tem sido a relação entre sujeitos com histórias singulares, irreproduzíveis e intransferíveis. Desde sempre, buscou-se uma explicação para o fenômeno do adoecimento psíquico e possíveis terapêuticas.

Como humanidade, temos nos organizado em convenções. Convenções ou consensos mínimos são acordos, agenciamentos, códigos universalizadores e universalizantes que norteiam e dão os limites socialmente aceitáveis, nas relações dos seres humanos entre si e entre grupos. São as leis, as normas, a ética, a moral e

\footnotetext{
* Entendendo tecnologia como "o próprio processo de trabalho em Saúde Mental onde se articulam um conjunto de saberes, instrumentos e práticas que, uma vez utilizados por e para pessoas, cria um campo intersubjetivo por excelência, com significado social inerente [...] um conjunto de práticas de natureza biológica, psicológica e sócio-antropológica atravessadas por afetos e idiossincrasias que, no campo da arte e da ciência, têm constituído o campo de práticas de cuidados às pessoas"(3)

E ainda: "a tecnologia, enquanto conjunto de saberes e instrumentos específicos apropriados para a reprodução das relações sociais, constituise dentro do processo de trabalho"(4)
} 
os conhecimentos postos a serviço da humanidade.

Se, por um lado, a convenção imprime um sentido redutor das manifestações humanas ao senso comum, de outro, propõe um caráter viabilizador de trocas e de continências (como continente e não como repressão), delimita aonde é possível chegar, um tempo, um espaço. A convenção ancora a experiência no campo das realizações e da possibilidade de repetição, se necessário for, podendo a experiência ou repetição ser um processo criativo, superador ou, então, meramente reiterativo.

A história da humanidade vem inscrevendo convenções sobre o que é doença e tratamento, numa dialética mediada pelas condições materiais e objetivas onde práticas em saúde podem ser identificadas. No campo da saúde mental, da mesma forma, podem ser identificados conceitos de adoecimento psíquico e terapêuticas operadas nos diferentes períodos de desenvolvimento político e econômico e da organização da sociedade, desde os primórdios até a idade contemporânea.

Os povos primitivos (e representantes desse tipo de organização social preservado até os dias atuais, como os povos indígenas) admitiam o transtorno mental como um fenômeno de causa mágico-religiosa identificado como possessão de espíritos maléficos. Para tal concepção de doença, desenvolveu-se uma tecnologia de cuidados operada pelo xamã ou sacerdote, com rituais de expulsão de espíritos, rezas e benzimentos. Dado que à convenção para o conceito de doença harmoniza-se uma convenção de tratamento, para cada concepção de processo saúdedoença corresponde uma determinada tecnologia de cuidados. Nos tempos atuais, algumas seitas e rituais religiosos também aderem a essa concepção de processo saúde-doença mental e operam com as mesmas tecnologias de cuidados.

$\mathrm{Na}$ Antigüidade greco-latina, a concepção de doença mental baseava-se nas causas naturais. Hipócrates (460-356 a.C.), por exemplo, descreveu a histeria como deslocamento do útero (hystera, do latim, matriz), um ente de vida própria cujo deslocamento provocava dispnéia, taquicardia e desmaios na mulher. A tecnologia de cuidados da Antigüidade greco-romana era composta por massagens corporais, dietas, passeios e viagens. Incluía matrimônio para virgens e viúvas ou fumegações vaginais com ervas aromáticas para atrair o útero para o seu lugar ${ }^{(5)}$. Os romanos prescreviam, ainda, atividades como tratamento. Galeno (cerca de 150 d.C.) afirmava que a atividade era o melhor médico da natureza. Portanto, para a concepção das causas naturais da doença, expressa num órgão do corpo humano, o tratamento também era no corpo, harmonizando ou antagonizando os sintomas com seu curso natural, por meio da atitude menos invasiva e mais contemplativa do médico greco-romano.

Na Idade Média, ou Idade das Trevas, a convenção sobre a doença mental, sob influência da Igreja Católica, retomou a concepção mágico-religiosa. Nesse contexto, as convenções eram ditadas pelas leis da Igreja, não sendo propriamente um campo de acordos e trocas. Nas relações entre os seres humanos, a lei natural era a diferença de lugar social (senhor e escravo) que seria superada somente na vida eterna. A forma de garantir esse equilíbrio era o exercício da caridade (para os senhores) e submissão (para os não-senhores e escravos). Ora, quem subvertia a ordem natural da diferença emanada de Deus, era herege ou profanador - louco.

A Idade Média desenvolveu duas tecnologias de cuidado para a loucura: a Inquisição e o banimento na Nau dos Loucos. A primeira foi uma forma cruel e cruenta de silenciar os detentores de saberes laicos, que ameaçavam o saber secular aprisionado pelo clero. Nesse contingente, morreram mulheres do povo que adquiriram conhecimentos de ervas medicinais, por meio da tradição oral, e exerciam grande influência popular - as bruxas. Morreram, também, anatomistas, astrólogos, cantores e poetas que disseminavam, por meio da arte, críticas sociais, além das histéricas, devassos, pródigos e hereges.

O louco pobre, não errático, caracterizando um outro tipo de despertencimento, era colocado na Nau dos Loucos e vagava pelos rios europeus até ancorar num lugar que o recolhesse ou remetesse novamente à errância ${ }^{(6)}$. Mais uma vez, denota-se coerência entre concepção do processo saúde-doença e tratamento.

No Renascimento, a concepção de loucura complexificou. O longo período de repouso das ciências laicas, experimentais, favoreceu o desenvolvimento da filosofia. No século XVI, o louco era entendido como o sujeito inadaptado ao processo de urbanização das cidades e da expansão, em todos os campos do saberfazer. Esse período pode ser caracterizado como a retomada das conquistas marítimas, da expansão das fronteiras geo-políticas, o retorno à filosofia grega e o afastamento da totalização da Igreja Católica. Exemplo disso foi René Descartes (1596-1650) fundador do Racionalismo moderno e do novo estatuto do homem 
clássico: o homem da razão ${ }^{(7)}$.

Dessa forma, a existência humana, distinta da existência de Deus, proposta pelo cogito cartesiano, discriminou, também, duas formas de existência dos seres humanos: o arrazoado e o desarrazoado. Essa foi a convenção da Idade Clássica para definir a loucura ou o transtorno mental. Isto é, se a razão humanizou o homem e o libertou da regência divina, a desrazão diferenciou o desarrazoado do homem humanizado e o aproximou da animalidade ${ }^{(6)}$.

Em 1656, em Paris, foi fundado o primeiro Hospital Geral, não com função de tratamento, mas de isolamento e controle social. A finalidade do Hospital Geral era acolher loucos, lascivos, pedófilos, usurpadores, mendigos, etc. ${ }^{(8)}$. Assim, a tecnologia para cuidar dos transtornados e outros despossuídos do Renascimento era o internamento que configurava ao desarrazoado a condição de animalidade.

Cabe ressaltar que a essa tecnologia de cuidados aderia uma prática e uma representação que perseguiu o que viria a ser a prática de enfermagem até o século XX. Tratava-se da função de vigilância, punição pelo uso de métodos coercitivos, por meio da força física ou de instrumentos disciplinadores, como a roda, banhos, acorrentamento, supressão de luz solar e isolamento ${ }^{(1)}$.

A Revolução Francesa, em 1789, e a Revolução Industrial, na Inglaterra, consolidaram a passagem do modo de produção feudal para o capitalista, rompendo os resquícios de uma determinada relação de subordinação entre os seres humanos (senhor e escravo) e inscrevendo outro tipo de interdependência entre donos dos meios de produção e donos da força de trabalho. Nesse contexto, a loucura estava associada à inadaptabilidade do ser humano de incluir-se no mundo produtivo, de consumo e de acumulação $0^{(9)}$. A loucura era confundida com ociosidade.

Guiado pelos ideais Iluministas de Liberdade, Igualdade e Fraternidade, Philippe Pinel, em 1793, quando foi indicado para Bicêtre, capturou a loucura para o campo médico, libertando-a da animalidade. É consenso entre autores $^{(5-6,8,10-12)}$ que esse ato e essa data fundaram a psiquiatria, como campo da medicina moderna, e a medicalização da loucura, pois, utilizando os métodos da medicina classificatória, Pinel propôs a um só tempo:

- Uma nosografia - o corpo conceitual de base científica que inscreveu a loucura nas categorias médicas e a ela deu o estatuto de doença mental, diferenciando-a da ociosidade;

- Uma relação específica entre o médico e o doente, onde o primeiro dizia a verdade da doença pelo saber que tinha dela e poderia submetê-la pelo poder que sua vontade exercia sobre o doente;

- Um lugar, o manicômio, onde a medicina podia descobrir a verdade da doença, afastando tudo o que podia mascarála, confundi-la ou dar-Ihe formas bizarras ${ }^{(8)}$.

Essa é a síntese alienista ${ }^{(9)}$ que definiu a convenção de transtorno mental do século XIX. Ou seja, o louco, diferentemente dos outros excluídos, era passível de tratamento porque a causa da sua doença era a paixão pervertida. Para uma concepção de doença de cunho médico-moral, a tecnologia de cuidados do século XIX foi o Tratamento Moral, que tratava a paixão pervertida do doente por meio da influência da paixão reta do médico, pelo exercício da disciplina e pelo uso do trabalho do doente como forma de adaptabilidade e utilidade social.

\section{A SíNTESE ALIENISTA E SEUS DESDOBRAMENTOS}

A síntese alienista foi o divisor das águas da antiga concepção de loucura para o enquadre deste fenômeno no campo médico. Desde sua constituição, não foi mais possível uma convenção única para o entendimento do processo de adoecer e tratar.

Um dos desdobramentos da síntese alienista foi o que investiu na busca da causalidade biológica para compreensão do processo saúde-doença com expressão moral ou comportamental e na investigação do lugar onde esta se alojava. Essa perspectiva vem ocupando o pensamento psiquiátrico, desde o século XIX até nossos dias.

Iniciou com a classificação nosográfica dos transtornos mentais de Pinel e foi desenvolvida por seu seguidor, Esquirol (1772-1840). Posteriormente, Emil Kraeplin (1856-1926) desenvolveu uma nosografia baseada no curso natural da doença, a partir do curso evolutivo dos quadros nosográficos. Ainda no campo da pesquisa médica, Karl Jaspers (1883-1969) propôs a classificação que deu origem à corrente psicopatológica, de inspiração fenomenológica, e Eugen Bleuler, em 1911, cunhou o termo esquizofrenia (cisão da mente) para um grupo de doenças com uma sintomatologia comum ${ }^{(5)}$.

Da mesma forma, as investigações biológicas seguiram-se por todo o século XIX, com somatistas franceses como Falret (1794-1870), Baillarger (1809-1890), 
Tours (1804-1884), precursor da farmacologia, Bayle (17991858), Morel (1809-1873) com a teoria da degenerescência e Magnan (1835-1912), com a teoria da hereditariedade, todos de tradição racionalista e empirista, além da contribuição do anatomista alemão Griesinger (18171868) $)^{(5)}$.

Entretanto, o grande boom dessa vertente, chamada biológica ${ }^{(5)}$, ocorreu nos anos 90 do século XX, com o desenvolvimento das neurociências e da medicina por imagens. A possibilidade de investigar as reações neuropsicológicas por imagens, sem procedimentos invasivos, alimentou, de forma consistente, o ideal da localização da sede da doença mental ${ }^{(13)}$. No contexto médico, a atualização nosográfica, aliada à investigação da causa biológica da doença mental, compôs uma convenção aceita globalmente como a referência para a classificação dos transtornos mentais, incluída na Classificação Internacional das Doenças (CID-X) da Organização Mundial de Saúde.

Um outro desdobramento da apropriação médica da loucura, proposto por Sigmund Freud, no final do século XIX, com a descoberta do inconsciente e a construção da base teórica da Psicanálise, inaugurou uma convenção para entender o funcionamento psíquico, dimensão que escapava ao controle da ciência experimental da razão.

Esse olhar, desenvolvido pelas correntes de pensamento e práticas que antagonizavam a psiquiatria biológica, como as comunidades terapêuticas, na década de trinta; a psiquiatria comunitária, na década de cinqüenta $^{(14)}$, a psiquiatria democrática italiana a partir da década de sessenta e a atual tendência às práticas comunitárias, no Brasil, possibilitaram a construção do que é hoje chamado de modo psicodinâmico de compreender o transtorno mental, situando o portador do transtorno numa rede de relações onde a história, a família, a constituição do próprio sujeito, dizem mais do que a simples apresentação de sinais e sintomas.

Diferentemente do Tratamento Moral, onde o saber médico dizia a verdade da doença e submetia a vontade deturpada do doente à sua, pelo poder que tinha sobre ele ${ }^{(8)}$, essa perspectiva fundou a relação humana entre quem trata e quem é tratado, colocando ambos como atores do processo clínico(15). Aderido ao modo psicodinâmico de compreender o transtorno mental, desenvolveu-se uma tecnologia de cuidados, atualmente denominada Campo Psicossocial ${ }^{(16)}$.

Dessa forma, é possível concluir que o atual estágio de desenvolvimento tecnológico e teórico na área da saúde admite duas grandes convenções para duas concepções hegemônicas do processo de adoecimento mental (campo biológico e psicossocial) e reitera que, para uma determinada concepção de adoecer, correspondem determinadas formas de tratar, forjadas historicamente, isto é, no desenvolvimento das condições concretas e materiais desse dado momento histórico.

Grosso modo, admite-se, também, que o campo biológico goza de maior visibilidade, resolutividade e reconhecimento social, por ter sido construído nos pressupostos da ciência positiva. Por outro lado, o campo psicossocial demanda a construção e a consolidação das bases teóricas e conceituais que fundam sua prática, uma vez que vem sendo forjado num mosaico de referências, na interface com a filosofia, com as ciências sociais e humanas ${ }^{(17)}$. Essa tarefa é particularmente árdua para a enfermagem, que vem construindo suas teorias de cuidados e desenvolvendo seus instrumentos de intervenção, de forma orgânica, com o desenvolvimento da medicina científica e instrumental.

\section{CONSIDERAÇÕES FINAIS}

A linha de pensamento construída até aqui buscou desvelar a íntima e necessária relação entre concepções de processo saúde-doença e as terapêuticas historicamente utilizadas no enfrentamento da loucura. É de se notar que a loucura ou doença mental sempre esteve vinculada ao despertencimento, ao lugar de ninguém, do sem nome, e que os mecanismos de controle engendrados pré e pós medicina moderna encetavam a normatização, a subordinação à ordem, o enquadre à razão moderna. $O$ esforço da medicina em nomear, classificar, buscar instrumentos para intervir no adoecimento psíquico descreve um desenho homogêneo, onde não há surpresas, isto é, se a loucura é a errância, o despertencimento, bane-se. Se for a desrazão, enjaula-se. Se for a ociosidade, submete-se ao trabalho.

No século XX, a psiquiatria passa a confrontar-se com os desdobramentos da síntese alienista e a conseqüente construção de modelos assistenciais a eles aderentes, com a construção de corpos de conhecimentos universais (nosografias, farmacoterapias, etc.) e particulares (teorias e técnicas específicas), atinentes a cada prática social em saúde, parceladas na sua própria gênese. 
Além disso, observa-se que, aliado ao interesse sanitário, há uma relação sintônica entre a detecção e o tratamento da doença mental e os interesses socioeconômicos e políticos dominantes. De outra forma, e particularizando o caso do Brasil, a mais forte mediação para um projeto de saúde - da colônia à República recém instaurada - foi econômica e mercantil, referida ao controle endêmico e epidêmico de doenças, secundarizando, de forma inequívoca, as necessidades de saúde da população local. Na saúde mental, as políticas de saúde responderam ao clamor da ordem social, prestando-se ao controle dos alienados e oferecendo-Ihes minoridade social e tutela jurídica, desde a década de trinta, do século XX.

A situação não parece substancialmente diferente na atualidade, visto o vigor da medicina privada, os convênios médicos e, na área da saúde mental, os mais de sessenta mil leitos psiquiátricos que movimentam uma saudável indústria hospitaleira. No entanto, com o atual nível de desenvolvimento das condições objetivas de vida, qual será o enigma da loucura, ou da doença mental, para a medicina? Os doentes não são mais erráticos, não são animais de circo, e a ociosidade passou a ser um horizonte, não pela exclusão, mas pela nova racionalidade humana ${ }^{(18)}$. Além disso, os excluídos do mundo do trabalho são muitos, não apenas doentes mentais. Assim, o que sustentará as terapêuticas para a loucura ou doença mental no século XXI? As práticas comunitárias, amparadas no campo psicossocial afirmam os direitos de cidadania, o tratamento como direito, a autonomia dos sujeitos. As práticas biológicas sustentam a racionalidade técnica, a investigação orgânica e o desenvolvimento de instrumentos construídos nos laboratórios. Qual será a finalidade do trabalho em saúde mental ou da psiquiatria nestes tempos onde a loucura circula nos espaços públicos, e a tendência da humanidade é circular pelos espaços cibernéticos?

Tal discussão convoca os prestadores de assistência e os formadores da força de trabalho em saúde mental para uma atualização conceitual e ética, uma vez que a proposição soa impertinente para o modelo tradicional, cuja finalidade do processo de trabalho é a adaptabilidade e o controle social; o objeto de intervenção é a doença e pressupõe que a concepção do projeto terapêutico seja privativa dos profissionais, excluindo percepções e saberes do portador do transtorno mental, que podem ser sinalizadores de um projeto singularizado e que faça sentido na sua particular experiência de adoecimento. Não se pode esquecer que a maioria das instituições formadoras, em todas as áreas, alinham-se a esses pressupostos.

No que concerne à enfermagem, diversos estudos $^{(9,19-23)}$ indicam que as atividades desempenhadas pelos enfermeiros da área da saúde mental, localizam-se prevalentemente em hospitais psiquiátricos e "são, em sua maioria, burocrático-administrativas. A assistência de enfermagem é baseada no modelo biológico, cujas ações consistem em higiene, alimentação, administração de medicamentos, vigilância e controle dos internos"(9).

Ainda segundo a autora, no campo do ensino, os docentes "adotam como referência [...] autoras ${ }^{(21-22)}$ que definem o papel do enfermeiro como o de agente terapêutico"(9) (Grifo meu). Entretanto, evidencia-se uma contradição em relação ao instrumento de intervenção proposto, no caso, o relacionamento terapêutico enfermeira-paciente, que propõe ao profissional que "faça uso de sua personalidade para ajudar a pessoa doente a desenvolver suas possibilidades de saúde". Todavia, "a assistência está centralizada na identificação de sinais e sintomas - a doença, e a finalidade é a remissão desses sintomas e a conseqüente mudança de comportamento a cura" ${ }^{\prime(9)}$.

Dessa forma, constata-se que os formadores de força de trabalho em enfermagem reiteram ideologicamente o modelo tradicional e, além disso, "no que tange ao cuidar, parece ser prevalente a visão da enfermagem vocacional, sustentada mais pelo pilar ético da caridade que da solidariedade. A humanização do cuidado é obtida por meio do estabelecimento de relações amigáveis com a clientela e não por meio de transformações nos conteúdos das práticas"(24). Como agravante, os modelos de assistência que antagonizam o modelo tradicional ou a ética vocacional, são escassos de visibilidade.

Por outro lado, o estudo desenvolvido num serviço comunitário, de visibilidade nacional, cujos marcos conceituais adotados institucionalmente alinham-se e sustentam os pressupostos da Reforma Psiquiátrica, indicou que um modelo de assistência para a população usuária dos serviços de saúde mental desse final de século deve considerar e estruturar-se a partir das necessidades expressas da população usuária, individual e familiar ${ }^{(1)}$.

Segundo esse estudo, a construção compartilhada do projeto terapêutico desloca a população usuária - indivíduo e família - do lugar de submetida (a um projeto definido pelos profissionais) para o lugar de aliada na construção de resoluções para os seus agravos de 
saúde. A construção coletivizada do projeto terapêutico, que pressupõe o tratamento como um direito e não como controle social, "indica a adesão efetiva ao serviço, favorece a organização social e política do usuário (com representação no Conselho Administrativo do PIDA, Comissão Estadual de Saúde Mental e Comissão Nacional de Reforma Psiquiátrica) e amplia individualmente o seu grau de autonomia, garantindo o preceito básico de cidadania que é o de ir e vir"(1).

Ressalta-se o fato de que as necessidades dos usuários-trabalhadores (tais quais as da população em geral) foram produzidas e impostas pelo próprio desenvolvimento das forças produtivas, como: necessidade de ganhar dinheiro, viver dignamente, ter acesso aos bens de consumo, ter uma vida afetiva e amorosa estável, além do tratamento clínico, no seu sentido mais estrito ${ }^{(1)}$.

\section{REFERÊNCIAS BIBLIOGRAFICAS}

1. Silva ALA. O Projeto Copiadora do CAPS: do trabalho de reproduzir coisas à produção de vida. [dissertação]. São Paulo (SP): Escola de Enfermagem/USP; 1997.

2. Peduzzi M. Equipe multiprofissional de saúde: a interface entre trabalho e interação. [tese]. Campinas (SP): Faculdade de Ciências Médicas/Unicamp; 1998.

3. Ministério da Saúde (BR). 2ª Conferência nacional de saúde mental. Brasília (DF): Ministério da Saúde; 1994.

4. Lana FCF, Rocha SMM. Organização tecnológica do trabalho em hanseníase com a produção de poliquimioterapia. In: Almeida MCP, Rocha SMM, organizadoras. O trabalho de enfermagem. São Paulo (SP): Cortez; 1997. p.113-50.

5. Louzã MR Neto, Motta T, Wang Y-P, Elkis H. Psiquiatria básica. Porto Alegre (RS): Artes Médicas; 1995.

6. Foucault M. História da loucura na Idade Clássica. 4ª ed. São Paulo (SP): Perspectiva; 1995.

7. Descartes R. Os Pensadores. São Paulo (SP): Nova Cultural; 1987

8. Foucault M. Microfísica do poder. 11aㅡ ed. Rio de Janeiro (RJ): Graal; 1993.

9. Barros S. O louco, a loucura e a alienação institucional: o ensino de enfermagem sub-judice. [tese]. São Paulo (SP): Escola de Enfermagem/USP; 1996.

10. Foucault M. Doença mental e psicologia. 4a ed. Rio de Janeiro (RJ): Tempo Brasileiro; 1991.

11. Kaplan HI, Sadock BJ. Compêndio de psiquiatria. $2^{\underline{a}}$ ed. Porto Alegre (RS): Artes Médicas; 1993.

12. Silva JF Filho. A medicina, a psiquiatria e a doença mental. In: Tundis SA, Costa NR, organizadores. Cidadania e loucura: política da saúde mental no Brasil. Petrópolis (RJ): Vozes/ Abrasco; 1987. p. 75-102.

13. Gleiser M. Imagens do cérebro. Folha da São Paulo. São Paulo (SP); 18 de jun. 2000. Mais!. p. 29.

14. Pitta AMF. Reabilitação psicossocial: um novo modelo? In: Lauar $\mathrm{H}$, organizador. A psiquiatria e suas conexões: política biologia filosofia. Belo Horizonte (MG): Associação Mineira de Psiquiatria; 1996. p. 48-52.
Parece que um modelo de atenção pautado nos pressupostos do Campo Psicossocial ${ }^{(15)}$, da Clínica Ampliada $^{(25)}$, e no conceito de reabilitação psicossocial ${ }^{(26-}$ 27) pode ajudar a clarear esse campo ainda pouco explorado da intervenção de enfermagem.

Esse novo campo tem, como pressupostos, para os prestadores da assistência, o planejamento do projeto de intervenção coletivizado, a superação da rigidez dos papéis e das especificidades profissionais, a flexibilidade para responder ao parâmetro fundamental da assistência, que é o bem estar do usuário. Nesse sentido, a prática busca a ampliação da capacidade de entendimento e a apropriação do controle do processo saúde-doença pelo usuário, a ampliação da sua capacidade de agenciar soluções no campo afetivo, material e social, e uma maior participação na vida política e jurídica.

15. Meola ME. O campo da saúde mental e as tecnologias de cuidados: uma reflexão. Rev Ter Ocup Univ São Paulo 1999; 10(1).

16. Saraceno B, Asioli F, Gianni T. Manual de saúde mental. São Paulo (SP): Hucitec; 1997.

17. Silva ALA e, Guilherme M, Rocha SSL, Silva MJP da. Comunicação e enfermagem em saúde mental - reflexões teóricas. Rev Latino-am Enfermagem 2000 outubro; 8(5):6570.

18. Morin E. As idéias. In: Morin E. O método - IV. Porto Alegre (RS): Sulina; 1992.

19. Saeki T. Caracterização das atividades do enfermeiro na assistência ao doente mental internado nos hospitais psiquiátricos do Estado de São Paulo. [dissertação]. Ribeirão Preto (SP): Escola de Enfermagem de Ribeirão Preto/USP; 1981.

20. Saeki T. Análise da prática do enfermeiro em um hospital psiquiátrico. [tese]. Ribeirão Preto (SP): Escola de Enfermagem de Ribeirão Preto/USP; 1994.

21. Filizola CLA. O papel do enfermeiro psiquiatra: oprimido e opressor. [dissertação]. São Paulo (SP): Escola de Enfermagem/USP; 1990.

22. Stefanelli MC. Relacionamento terapêutico enfermeira/ paciente. Rev Esc Enfermagem USP 1983; 17(1):39-45.

23. Taylor CM Fundamentos de enfermagem psiquiátrica. 13a ed. Porto Alegre (RS): Artes Médicas; 1992.

24. Fonseca RMGS da. Práticas de enfermagem em saúde coletiva: um olhar de gênero. [relatório de pesquisa] São Paulo (SP): Escola de Enfermagem da USP; 2000.

25. Goldberg JI. Clínica da psicose: um projeto na rede pública. $2^{\text {a }}$ ed. Rio de Janeiro (RJ): Te Corá/Instituto Franco Basaglia; 1996.

26. Basaglia F. Riabilitazione e controllo sociale. In: Basaglia F. Scritti II (1968-1980): dall'apertura del manicomio alla nuova legge sull'assistenza psichiatrica. Torino: Giulio Eunaudi; 1982. p. 199-208.

27. Saraceno B. Reabilitação psicossocial: uma estratégia para a passagem do milênio. In: Pitta $A$, organizadora. Reabilitação psicossocial no Brasil. São Paulo (SP): Hucitec; 1996. 